\title{
Teaching Practice of Engineering Mathematics Based on Kolb's Learning Style Theory
}

\author{
Yue Yang ${ }^{1, *}$ and Meili Zhang ${ }^{2}$ \\ ${ }^{1}$ Department of Mathematics, Dalian Naval Academy, Dalian, China 1 \\ ${ }^{2}$ Department of Mathematics, Dalian Naval Academy, Dalian, China 2 \\ *Corresponding author. Email: 49963964@qq.com
}

\begin{abstract}
This paper investigates and analyzes the distribution of learning styles of students in our college by using Kolb learning style scale, so as to deepen the understanding of learning styles and carry out the student-centered teaching reform for Engineering Mathematics. For teachers, studying learning style can help them design teaching methods suitable for students and teach students in accordance with their aptitude. For students, they can understand and improve their learning style, which not only increases the learning efficiency, but also improves the learning effect. The differences and diversity of individual students are the basic conditions for cultivating creative talents. It's necessary to take the cultivation of innovative talents as the goal, and systematically integrate and optimize the curriculum system, teaching content, teaching means, examination methods and teaching management.
\end{abstract}

Keywords: Learning styles, Kolb Learning style Scale, Student-centered teaching reform, Engineering mathematics.

\section{INTRODUCTION}

Learning style was first proposed by American scholar Herbert Thelen in 1954. Now it has become a common concern of western educational psychology, learning theory, teaching theory and other disciplines. In 1979, Keefe defined learning style from the perspective of information processing, "learning style is composed of learners' unique cognitive, emotional and physiological behaviors, and it is a relatively stable learning way for learners to perceive information, interact with and respond to learning environment" [1]. Generally speaking, learning style is a preferred or habitual attitude and the way in the process of personal perception, memory, thinking and problem solving. Learning style theory enriches educators' understanding of individual differences and is the basis of modern teaching method reform.

Kolb is one of the outstanding contributors in the field of learning style research, who discussed the learning process from the perspective of "experience". Based on the theory of experiential learning, starting from the way of thinking and information processing, he defined learning styles as concrete experience (CE), reflective observation (RO) and abstract conceptualization (AC) and active experience (AE).
Kolb believes that learning style is a preferred method of perceiving and processing information. The combination of these two dimensions constitutes a model to describe four different learning styles [2] (as shown in Figure 1)

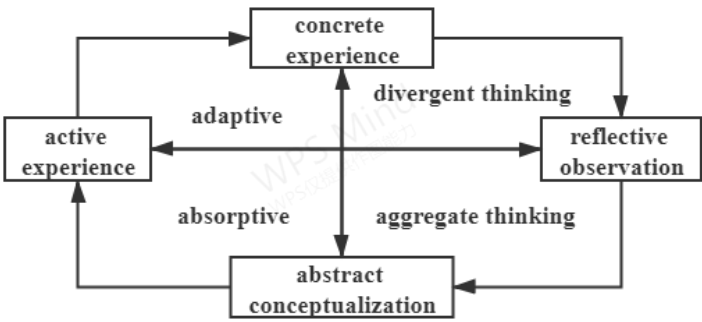

Figure 1 Kolb learning cycle and learning style

\section{RESEARCH VALUE}

Through the analysis of the above research, we think that further deepening the study of learning style has important practical significance. 


\subsection{The Theory of Learning Style Is the Basis of the Modern Teaching Methods Reform}

Although learning style is gradually formed by individuals in the long-term learning process with lasting stability, it still has plasticity and can be adjusted through learning content and environment in the later stage[4]. According to the learning style theory and research results, teachers can make corresponding adjustments in curriculum teaching and extracurricular practice.Teaching students in accordance with their aptitude and guiding them according to the circumstances are conducive to not only improving the quality of education, but also encouraging innovative thinking, cultivating innovative talents and achieving better results in engineering mathematics education.

\subsection{The Study of Learning Style Can Promote Both Students and Teachers}

Although learning style is closely related to stable and habitual learning style, it is not invariable in specific learning tasks. For students, studying learning style can better understand their preferred perception and information processing methods, adjust according to different learning requirements. It can give full play to their own advantages, make up for the deficiencies and improve learning efficiency. For teachers, they can understand students' cognitive tendency, respect students' learning style and help them develop suitable learning style for current learning tasks by improve students' learning quality. In addition, due to the close relationship between learning style and learning strategies and skills, teachers should pay attention to improving various skills related to their learning methods, try to adopt a variety of teaching forms to encourage students' actively participating in learning activities. By increasing specific experience, it can help students better accept information and carry out specific reflection and processing on the learned knowledge, so as to effectively improve the teaching effect and realize the goal of learning "Effective teaching".

\subsection{Teaching Students in Accordance With Their Aptitude Considering the Characteristics of Engineering Mathematics}

Engineering mathematics is a compulsory basic course for all majors in our college. It lays a solid theoretical foundation for students in linear algebra, probability theory and mathematical statistic. The course can cultivate students' ability of logical reasoning, induction and operation. It help students to analyze and solve practical problems, so as to provide necessary theoretical basis for further professional courses and engineering practice. However, the basic concepts in this course are relatively abstract and difficult to understand. Examples is very important, which puts forward higher requirements for students' mathematical foundation and learning ability.

\section{A SURVEY OF LEARNING STYLES OF STUDENTS IN MILITARY COLLEGE}

120 samples were randomly selected from grade two to four as examples for test. And the 1985 version of Kolb Learning Style Inventory (LSI)[5] was used, which contains 12 questions, describing kinds of learning situations. Combined with the analysis of Engineering Mathematics midterm examination results, statistical software is used. Chi square test is used for counting data, and ANOVA is used for measuring data. The test level is .

Finally, 103 qualified questionnaires were obtained. According to the questionnaire each student's learning style type was determined and academic performance were compared for statistical analysis. The academic achievement is selected as the weighted average score of each course in the first semester. This is due to the fact that after the second semester, students' performance is often greatly influenced by factors other than learning style. The difference between the average scores of the three grades is only 2 points at most, so it is not treated separately. The reason why students of the same major are selected for this survey is to avoid the possible impact of the differences in the number of courses, course contents and teaching conditions of students from different majors.

From the statistical results of the survey showed that the number of people with various learning styles and the obvious law of learning style change from lower grade to higher grade, the survey method is basically correct and the results are reliable. The main conclusions are as follows

(1) The distribution of learning style types of 103 students showed that the majority (about 63\%) preferred specific experience in perception style, about $37 \%$ preferred abstract generalization, and about 50\% preferred reflective observation and active practice in information processing style.

(2) According to the proportion of students with four learning styles in different grades, the number of students with divergent thinking style is gradually decreasing, while the number of students with other styles is gradually increasing, and the law is obvious. The change mainly occurs in the third academic year, which might be related to the great differences in learning content (mainly professional courses and practical courses) and learning requirements at this stage compared with the past.

(3) According to the statistics of the academic performance of various learning styles, the excellent students are mainly distributed in the aggregate thinking 
style and absorption style with a small number of students, and the performance differentiation is very significant in the aggregate thinking style. This might be related to the respondents from engineering majors, the teaching methods in military academies and the students' physical and mental conditions.

\section{TEACHING PRACTICE OF ENGINEERING MATHEMATICS}

The teaching of engineering mathematics is not only to impart knowledge to students, but also to cultivate students' self-study ability and the capacity to analyze and solve problems. These two important aspects are indispensable and complementary. However, it is of great practical significance to stress ability training.

\subsection{Paying Attention to Differences in Learning Styles}

Individual learning styles are unique, so teachers should establish the concept of different teaching. They should try to provide students with the opportunity according to the advantages of their own learning styles and enhance their learning motivation and enthusiasm. Learning style is multidimensional. Teachers should dialectically treat the relationship between students' learning style and their own teaching style. Thus they could establish a fair teaching concept and cannot discriminate against and neglect students who do not match their own teaching style.

To a certain extent, learning style is the unity of stability and plasticity. Teachers should have the concept of development in teaching. They should not only give full play to the advantages of students' existing learning style, but also make up for the disadvantages. Then students' personality characteristics are expected to be more prominent and they can develop more comprehensively.

\subsection{Teaching Behaviors Concerning Learning Style Differences}

\subsubsection{Teaching Design}

According to the principle of combining unity and difference, teachers can establish the unified goal for all students and the specific goal for students with different learning styles. They should have specific ideas of classroom teaching, so as to provide each kind of learning style with the opportunity to learn in their preferred way. They could choose different teaching forms considering different learning styles, adopt appropriate teaching media and flexible teaching methods. And the organic combination of different teaching forms, teaching media and teaching methods is also noticeable.

\subsubsection{Teaching Implementation}

Teachers should pay attention to the learning needs of students with different learning styles in each teaching process. It's advised to divide classroom teaching into three parts as presenting information, explaining information and consolidating information.In the process of presentation, teachers can present new knowledge in the way they are good at or like, and then try to present new knowledge in other different ways. In the process of explaining knowledge, teachers try to use a variety of ideas and viewpoints to analyze problems as much as possible to match teaching strategies. By selfstudy discussion and group cooperative learning, students with different learning styles can learn from each other. It can not only cultivate the ability of independent thinking, but also let students learn from the ideas of teachers and other students. In the process of reviewing and consolidating teaching, teachers should also try their best to adopt a variety of methods to consolidate memory, such as speech analysis, image description and sound stimulation. They can stimulate the internal relationship between new knowledge and old knowledge and form the network system of the dominant characteristic knowledge in the cognitive structure of the students.

\subsubsection{Teaching Evaluation}

Teachers should update the teaching idea and reform the evaluation system. It's better to appropriately reduce the class size, improve teaching facilities and create a good external environment for paying attention to students' learning style differences. Classroom teaching evaluation should focus on the comprehensive improvement of students' learning quality. It not only guide students to play their learning style strengths, but also to make students clear their weaknesses and find ways to make up. Since different students often adapt to different teaching methods, the evaluation methods should be different.

\section{CONCLUSION}

Today large class teaching is universal in our country's universities. In order to realize the classroom teaching considering students' learning style differences, there are a lot to do with the quality of teachers, teaching conditions, school management and so on. The most important is that teachers know it and can correctly treat the differences of students' learning styles. Having this concept, they would do their best in the teaching design and process. With the deepening of the study of learning style and the improvement of teaching conditions, it is believed that "paying attention to the differences of students' learning style" will become a vivid teaching practice not just the slogan. And the idea of giving full play to each student's potential in all aspects will become a reality. 


\section{AUTHORS' CONTRIBUTIONS}

By studying Kolb's learning style theory and collecting our students' learning style data, we can grasp the learning style characteristics of engineering military students and deepen the understanding of individual differences. It is not only helpful to improving the quality of Engineering Mathematics education, but also conducive to cultivating innovative talents.

\section{ACKNOWLEDGMENTS}

Thanks for the support of college's 2020 education fund. Thanks for the help of my colleagues and the cooperation of our students.

\section{REFERENCES}

[1] Keef. J. W. Learning Style: An overview [A], in: In Student Learning Styles: Diagnosing and Prescribing Programs. Reston, VA: NASSP, 1979.

[2] Lu Genshu, Yu Dehong. Learning style and college students' Autonomous Learning. Xi'an Jiaotong University Press, 2003.

[3] Lu Juan, $\mathrm{Xu}$ Jinsong, Cheng Chuanmiao. Relationship between Kolb learning style types and VARK learning style types of military students, in: Chinese Journal of health psychology, No. 2, 2016.

[4] Tan Ding Liang. On learning style and its research value, in: Journal of Nanjing Normal University (SOCIAL SCIENCE EDITION), 1994, (3).

[5] Kolb. D. Experiential LearningF. NJ : Prentice Hall ,1984. 